\title{
Message Admission Control along with Buffer Space Advertisement to Control Congestion in Delay Tolerant Networks (DTNs)
}

\author{
Faiza Farooq, Nargis Bibi \\ Department of Computer Science Fatima Jinnah Women University Rawalpindi, Pakistan \\ faizafarooq699@gmail.com,nargis@fjwu.edu.pk
}

\section{Abstract}

Delay and Disruption Tolerant networks (DTN) are subject to intermittent connection and long delay, thus the internet congestion control mechanisms are not suitable for DTNs. Data Delivery Rate and Delivery Delay are the parameters affected badly when network or part of a network is in congestion. In recent years, Congestion control strategies in DTNs are considered an active area for research. In this research a hybrid congestion control mechanism, Message Admission Control with Buffer Space Advertisement (MACBSA) is proposed which is based on MaxProp routing protocol. Preliminary results show the improvement in network performance while utilizing network resources efficiently.

Keywords: DTN, Opportunistic Contacts, Intermittent Connectivity, Congestion Control, ONE.

Received on 23 November 2017, accepted on 12 March 2018, published on 10 April 2018

Copyright (C) 2018 Faiza Farooq and Nargis Bibi, licensed to EAI. This is an open access article distributed under the terms of the Creative Commons Attribution licence (http://creativecommons.org/licenses/by/3.0/), which permits unlimited use, distribution and reproduction in any medium so long as the original work is properly cited.

doi: 10.4108/eai.10-4-2018.154457

\section{Introduction}

In TCP/IP networks, continuous end-to-end connection is guaranteed. The routing protocols work on the assumption that complete route can be established from source to destination. Delay and Disruption Tolerant network (DTNs) are the networks that lack continuous network connectivity thus guarantee no end to end connection [1]. Routing between the non-fixed locations of nodes is a challenging task. Routers are used to forward the packet in TCP/IP. In extreme scenarios, if the link between routers is not available, TCP/IP simply discards the packet which reduces reliability. DTN is a solution to this scenario, which has been proposed by National Aeronautics and Space Administration (NASA) in which hop to hop reliability is maintained by using custody transfer [2]. For DTNs, there is a store-carry and forward approach, thus more disruption tolerant than TCP/IP [3]. Routers store the incoming packet in their memory chip or buffer by implementing bundle layer, in order to find the next hop and lookup there routingtable to decide the route. Passive routing and Active Routing are the two main divi

sions of Stochastic Routing scheme that are preferable as topology can be changed any span of time[2, 4]. In DTNs, one copy of message is not sufficient to obtain acceptable delivery ratio, thus replication of message such as flooding mechanism is used. By increasing no. of replication, delivery rate can be increased, while considering infinite number of network resources. In reality network resources are limited which leads to the stage of head of line blocking considered as congestion. Like TCP/IP, performance of the DTN's depend on many factors such as latency, probability of packet delivery, congestion control, flow control, overhead ratio, hop count, goodput and buffer space utilization. As it is significant to ensure the delivery of packet on time, but congestion occurrence affects the performance of DTNs badly. Congestion control mechanism is required to improve the performance measure of DTNs in term of Latency, Delivery Ratio, and the delivery cost known as 
overhead [5]. In this work the challenging issues of DTNs are studied, and existing congestion control mechanisms are investigated such as open-loop, close-loop and hybrid. The Research hypothesis is to investigate the existing congestion control techniques for simulating a hybrid scheme to control receipt and forwarding of packet for reducing Latency, increasing Delivery Ratio and minimizing the Overhead Ratio. The key contribution of this research is to reduce congestion in DTNs by using the proposed hybrid model. In addition to improve Delivery Ratio, while, decreasing Latency, and to utilize network resources efficiently in order to reduce overhead ratio. The remaining work is organized as: Section 2 begins with state of the art congestion control techniques. In Section 3, methodology is presented. Simulation parameters and performance evaluation is discussed in Section 4. Section 5 contains the results of simulation. Finally, the paper is concluded in Section 6

\section{Related Work:}

It is important to consider the routing protocols in congestion control scheme, as some congestion control techniques such as the technique presented in [6-22] depend on the routing protocols and underlying environment, while some mechanisms like [23-31], [5] are independent of the routing protocol that is being used. Successful transmission of data in intermittently connected networks is a challenging task. The routing protocol used for these networks should be more intelligent than the protocol used in TCP/IP network. Some routing protocols like Direct Delivery, FC, Seek and Focus, VADD, FFRDV and GeOpps use forwarding technique. Other protocols like Epidemic, Spray and Wait, PROPHET, MaxProp and RAPID use the replication mechanism. While few of the existing protocols work on the combination of forwarding and replication mechanism such as GeoSpray, VDTN-ToD, TrendOfSpray, PROPHET(+/or) ToD [3]. In Table 1, Table 2 and Table 3 a summary of current congestion control efforts is presented.
Table 1. Summary of closed-loop congestion control mechanism

\begin{tabular}{|c|c|c|c|c|c|}
\hline S\# & Mechanism & $\begin{array}{l}\text { Routing } \\
\text { Protocol }\end{array}$ & $\begin{array}{l}\text { Congestion } \\
\text { Detection }\end{array}$ & $\begin{array}{l}\text { P/R/H } \\
\text { Control }\end{array}$ & Contacts \\
\hline 1 & $\begin{array}{l}\text { Hop by Hop local } \\
\text { flow control [23] }\end{array}$ & Independent & $\begin{array}{l}\text { Network } \\
\text { Capacity }\end{array}$ & Hybrid & Scheduled \\
\hline 2 & $\begin{array}{l}\text { Custody Transfer by } \\
\text { Pushing-Pulling } \\
\text { Strategy [26] }\end{array}$ & Independent & $\begin{array}{l}\text { Buffer Avail- } \\
\text { ability }\end{array}$ & Reactive & Predicted \\
\hline 3 & Storage Routing [6] & Dependent & $\begin{array}{l}\text { Buffer Avail- } \\
\text { ability }\end{array}$ & Reactive & $\begin{array}{l}\text { Scheduled \& } \\
\text { Predicted }\end{array}$ \\
\hline 4 & $\begin{array}{l}\text { Advertising Buffer } \\
{[28]}\end{array}$ & Independent & $\begin{array}{l}\text { Buffer Avail- } \\
\text { ability }\end{array}$ & Proactive & Opportunistic \\
\hline 5 & Path Avoidance [7] & Dependent & $\begin{array}{l}\text { Buffer Avail- } \\
\text { ability }\end{array}$ & Hybrid & Predicted \\
\hline 6 & TBCC [25] & Independent & $\begin{array}{l}\text { Network } \\
\text { Capacity }\end{array}$ & Proactive & Predicted \\
\hline 7 & RBCC [24] & Independent & $\begin{array}{l}\text { Buffer Avail- } \\
\text { ability }\end{array}$ & Hybrid & Predicted \\
\hline 8 & CRSG [27] & Independent & $\begin{array}{l}\text { Buffer Avail- } \\
\text { ability }\end{array}$ & Reactive & Opportunistic \\
\hline 9 & $\begin{array}{l}\text { CAFA (Congestion } \\
\text { Aware) [12] }\end{array}$ & Dependent & $\begin{array}{l}\text { Buffer Avail- } \\
\text { ability }\end{array}$ & Proactive & Predicted \\
\hline 10 & $\mathrm{CBCC}[30]$ & Independent & $\begin{array}{l}\text { Buffer Avail- } \\
\text { ability }\end{array}$ & Hybrid & Opportunistic \\
\hline 11 & LTP-T [15] & Dependent & $\begin{array}{l}\text { Buffer Avail- } \\
\text { ability }\end{array}$ & Reactive & Scheduled \\
\hline 12 & IMRASFC [10] & Dependent & $\begin{array}{l}\text { Buffer Avail- } \\
\text { ability }\end{array}$ & Hybrid & Opportunistic \\
\hline 13 & $\mathrm{CCC}[13]$ & Dependent & $\begin{array}{l}\text { Buffer Avail- } \\
\text { ability }\end{array}$ & Hybrid & Scheduled \\
\hline 14 & RRCC [11] & Dependent & Drop Rate & Hybrid & $\begin{array}{l}\text { Predicted \& } \\
\text { Opportunistic }\end{array}$ \\
\hline 15 & $\begin{array}{l}\text { CAFE(Context } \\
\text { Aware) }[8,9]\end{array}$ & Dependent & $\begin{array}{l}\text { Buffer Avail- } \\
\text { ability }\end{array}$ & Hybrid & Predicted \\
\hline 16 & MACRE [20] & Dependent & $\begin{array}{l}\text { Buffer Avail- } \\
\text { ability }\end{array}$ & Hybrid & Opportunistic \\
\hline 17 & CCT [14] & Dependent & Drop Rate & Reactive & Predicted \\
\hline 18 & ION [31] & Independent & $\begin{array}{l}\text { Network } \\
\text { Capacity }\end{array}$ & Proactive & Scheduled \\
\hline
\end{tabular}

Table 2. Summary of open-loop congestion control mechanism

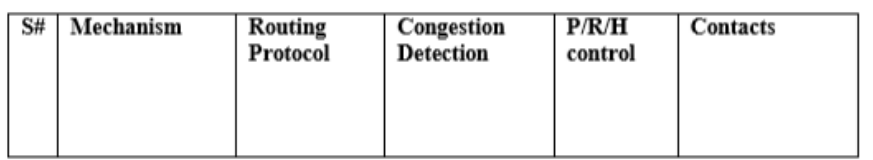

\begin{tabular}{|c|l|l|l|l|l|}
\hline $\mathbf{1}$ & $\begin{array}{l}\text { Following Rout- } \\
\text { ing [18] }\end{array}$ & Dependent & $\begin{array}{l}\text { Buffer Availa- } \\
\text { bility Reactive }\end{array}$ & Opportunistic \\
\hline $\mathbf{2}$ & CASPaR[21] & Dependent & $\begin{array}{l}\text { Network \& } \\
\text { Buffer }\end{array}$ & Proactive & Opportunistic \\
\hline $\mathbf{3}$ & AFNER [16] & Dependent & $\begin{array}{l}\text { Network Ca- } \\
\text { pacity Hybrid }\end{array}$ & Opportunistic \\
\hline $\mathbf{4}$ & DPRM [29] & Independent & $\begin{array}{l}\text { Buffer Availa- } \\
\text { bility Proactive }\end{array}$ & Opportunistic \\
\hline $\mathbf{5}$ & SARM [17] & Dependent & $\begin{array}{l}\text { Buffer Availa- } \\
\text { bility Reactive }\end{array}$ & $\begin{array}{l}\text { Predicted \& } \\
\text { Opportunistic }\end{array}$ \\
\hline
\end{tabular}

Table 3. Summary of Hybrid congestion control mechanism

\begin{tabular}{|c|l|l|l|l|l|}
\hline S\# & Mechanism & $\begin{array}{l}\text { Routing Pro- } \\
\text { tocol }\end{array}$ & $\begin{array}{l}\text { Congestion } \\
\text { Detection }\end{array}$ & $\begin{array}{l}\text { P/R/H } \\
\text { control }\end{array}$ & Contacts \\
\hline $\mathbf{1}$ & $\begin{array}{l}\text { Smart-DTN- } \\
\text { CC[5] }\end{array}$ & Independent & $\begin{array}{l}\text { Buffer Availabil- } \\
\text { ity }\end{array}$ & Hybrid & Adaptive \\
\hline $\mathbf{2}$ & DCCR [19] & Dependent & $\begin{array}{l}\text { Buffer Availabil- } \\
\text { ity }\end{array}$ & Hybrid & Opportunistic \\
\hline
\end{tabular}

\section{Admission Control along with buffer Space Advertisement (MACBSA):}

Mostly, in proactive techniques, admission control policies are used to avoid congestion before the transmission (forwarding and receipt of packet) starts. Admission rate is define as the adjustment of the input and output rate of a node. Admission control depends on the risk estimation value of the transmission. Buffer space of node, message's Time to Live (TTL), bandwidth 
availability and data rate etc are used for the calculation of risk value. Admission control technique tries to stimulate a congestion free environment. In MACRE, historical mean value of data rate is used to calculate risk value that reflects network status [20]. Node's input rate is compared with its output rate, if the output rate is greater than the input rate; node is allowed to receive the message. Else no more packets are received. This admission control's decision tells us whether to receive/accept a message or not, but lacks the facility to tell whether to relay/forward a message or not. It means that the chances are high that a message is relayed and then dropped because it only applies check on receipt of packet, but not on forwarding of packet. This is the drawback of MACRE [20], which was designed specifically for DTNs. Better results are supposed to be increased if check is applied on both receipt and forwarding of packet. Buffer Space Advertisement is another technique used for controlling congestion [28]. In Buffer Space Advertisement every node advertises a message in network which makes all the nodes aware from the state of buffer of adjacent nodes. In this way a global congestion control mechanism can be achieved by using a local scheme. Buffer size $(\mathrm{Ba})$ that will be advertised is to be calculated by multiplying congestion threshold (Tc) with the total size of the buffer (Bs) and then subtract the size of utilized buffer from it.

$$
\mathrm{B}_{\mathrm{a}}=\mathrm{T}_{\mathrm{C}} \times \mathrm{B}_{\mathrm{s}}-\mathrm{B}_{\mathrm{o}}
$$

The advantage of using the above formula is to deploy the safety margin. When message drop probability increases due to congestion, the nodes can use their safety margin to accommodate the packets instead of packet drop. Safety margin can be increased or decreased according to the requirement. By deploying this technique, a check on forwarding of packet is applied. If the advertised buffer size of next hop is less than the message size, then the packet is not forwarded.

Considering the characteristics of DTN and investigating the existing congestion control techniques, a hybrid technique is proposed i.e. Message Admission Control along with Buffer Space Advertisement to control congestion. This method combines the admission control [20] (for receipt) and buffer space advertisement[28] (for forwarding) in an efficient way for controlling the receipt and forwarding of packet.

If receipt and forwarding of packet is controlled, overhead ratio will surely be reduced, which shows that the network resources are utilized more efficiently and thus reduces the chances of arising congestion.

\section{Simulation and Performance Evaluation:}

To analyze the existing routing protocols along with congestion control algorithm Opportunistic Network Environment (ONE) simulator is used to conduct experiments. ONE simulator is preferred for the simulation, as it provides different mobility models, Routing protocols designed specifically for DTNs, different types of contacts that depicts real life scenario of DTNs, message handling and visualization, and also provide reports for analyzing. Helsinki city trace (of $4500 \mathrm{~m} \times 3400 \mathrm{~m}$ ) is used for mobility with Shortest Path Map Based movement model. Nodes are moved with an average velocity of $10 \mathrm{~km} / \mathrm{h}$ to $50 \mathrm{~km} / \mathrm{h}$. This simulation is carried out for high traffic (i.e. 1 message per 25-35 seconds) because focus of this study is on congestion that arises more in case of heavy traffic in an environment with limited resources. A denser network scenario is provided by this model. Simulation parameters are listed in Table 4.

Table 4. Simulation Parameters

\begin{tabular}{|c|l|l|}
\hline S\# & Parameter & Value \\
\hline 1 & Simulation time (s) & 43200 \\
\hline 2 & Buffer size (MB) & $2,3,4,5,6,7,8$ \\
\hline 3 & Message TTL (Minutes) & $10-60$ \\
\hline 4 & $\begin{array}{c}\text { Message generation interval (Sec- } \\
\text { onds) }\end{array}$ & $25-35$ \\
\hline 5 & Message size (MB) & $0.5-1$ \\
\hline 6 & No. of mobile nodes & 126 \\
\hline 7 & Interface Transmission Speed & $2 \mathrm{MB}=250 \mathrm{kbps}$ \\
\hline 8 & Interface Transmission Range & $100 \mathrm{~m}$ \\
\hline 9 & Wait time & 0,120 \\
\hline 10 & Mobility Model & $\begin{array}{c}\text { Shortest Path Map Based Move- } \\
\text { ment }\end{array}$ \\
\hline 11 & Speed (Km/h) & $10-50$ \\
\hline
\end{tabular}

\subsection{Evaluation Metrics:}

The following parameters are used to evaluate MaxProp along with Congestion Control techniques.

1. Delivery Ratio: Ratio of the number of messages received by the destination to the total number of messages generated by the sender.

2. Delivery Latency: Average delay in the reception of the packet.

3. Overhead Ratio of the message delivery: Ratio of difference between the number of packets forwarded by relay node and the number of packets delivered to the destination by the number of packets delivered. 


\section{Result discussion and analysis:}

The first experiment is conducted using heterogeneous message size with $2 \mathrm{MB}$ buffer size. Simulation is carried out for different TTL values between 10min to $60 \mathrm{~min}$. The observation is that by increasing message TTL the overhead ratio can be reduced for both plain MaxProp and MaxProp with congestion control mechanism. Figure 1 shows the performance of routing protocol in terms of overhead ratio along with congestion control mechanism in the shortest path map based movement model. Moreover, the plot shows that the proposed congestion control mechanism is very efficient for reducing overhead ratio. Figure 2 indicates the delay plot in which marginal gain in latency is observed. Figure 3 illustrates the performance evaluation in terms of delivery probability. Delivery probability is higher in case of MaxProp with congestion control mechanism. The second experiment is conducted using heterogeneous message size with buffer size between 2 to $8 \mathrm{MB}$. It is noted that the network parameters such as delivery probability, packet latency and overhead ratio are highly dependent on the buffer size hence experiments are conducted to present results as a function of buffer size. Figure 4 shows the delivery probability in terms of varying buffer size. This experiment is conducted by using 126 mobile nodes and message generation interval is random between [25, 35]. Same behavior is observed as previously conducted experiments. Increasing buffer size results in high delivery probability (i.e. approximately 1) but from 5.5 MB to onwards, no further improvement in delivery probability is observed. Figure 5 shows the effect of congestion control mechanism on overhead ratio. A comparison of the overhead ratio between congestion control mechanism and baseline scenario may be made. It shows significant reduction in the overhead ratio for both scenarios with an increase in the buffer size. Whereas, with smaller buffer size, the proposed technique makes a significant difference and reduces overhead ratio. Figure 6 shows the results obtained by calculating average latency against varying buffer sizes. At small values of buffer size, the latency is high for the proposed technique. Table 5 shows the normalized value of evaluation parameters with Shortest Path Map Based Movement Model in high traffic intensity, among varying message sizes. Simulation results show that, by using anticipated congestion control mechanism, significant amount of delivery ratio can be achieved along with the reduction of the overhead ratio; on the other hand latency is increased. The baseline scenario uses shortest path to find relay node, but the proposed technique adds the buffer occupancy constraint to find a relay node that may find a node to relay a packet on comparatively longer distance, which increases delivery probability however it also increases latency
Table 5. Normalized Parameters

\begin{tabular}{lcc}
\hline Routing scheme & MaxProp Router & MaxProp with CC \\
\hline Normalized Delivery Ratio & 0.712133 & 0.764883 \\
Normalized Overhead Ratio & 172.2125 & 158.6795 \\
Normalized Latency & 465.4171 & 482.0173 \\
\hline
\end{tabular}

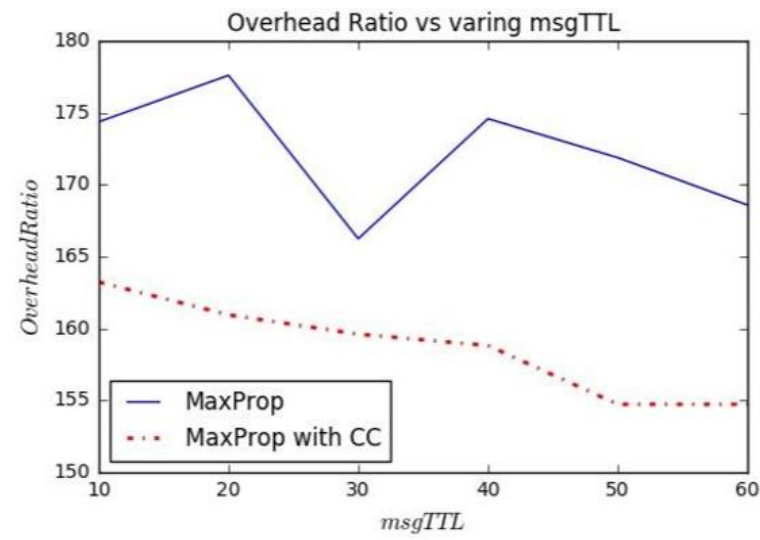

Fig. 1. Overhead ratio Vs varying Message TTL (Opportunistic network scenario, bandwidth of $250 \mathrm{Kbps}$, message generation interval of $25-35,126$ No. of nodes)

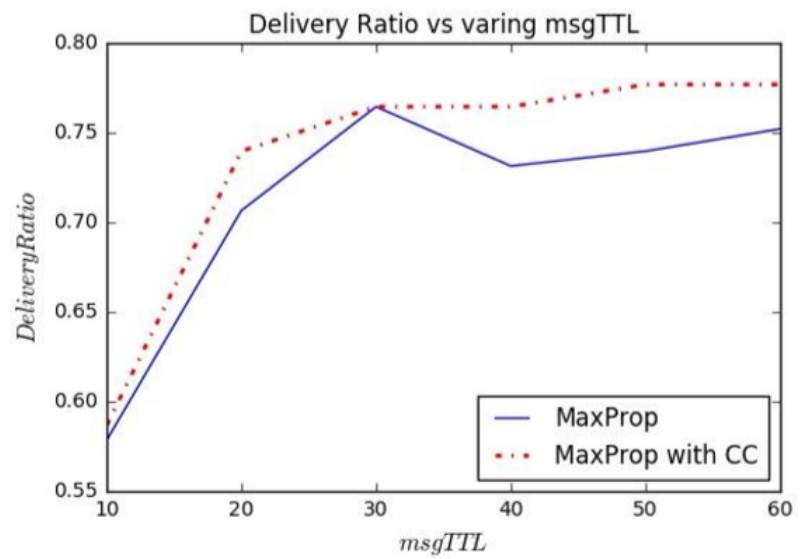

Fig. 2. Delivery ratio Vs varying Message TTL (Opportunistic network scenario, bandwidth of $250 \mathrm{Kbps}$, message generation interval of $25-35,126 \mathrm{No}$. of nodes)

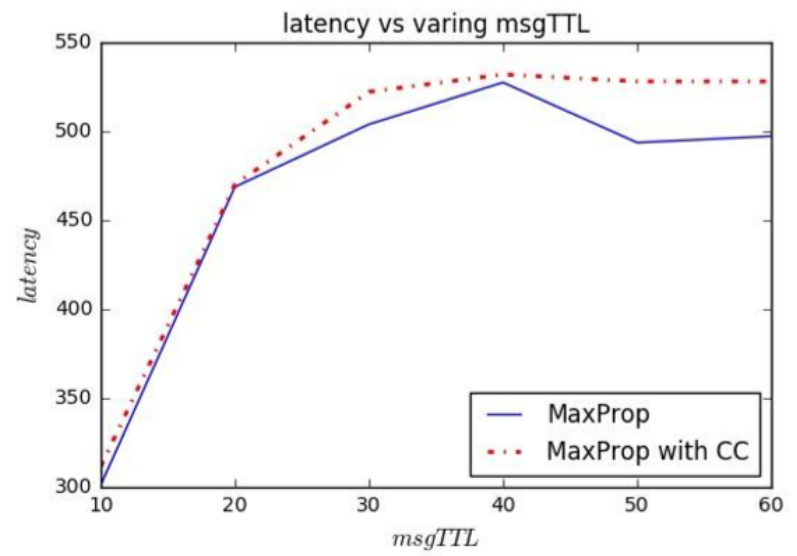

Fig. 3. Average Latency Vs varying Message TTL (Opportunistic network scenario, bandwidth of $250 \mathrm{Kbps}$, message generation interval of $25-35,126 \mathrm{No}$. of nodes) 


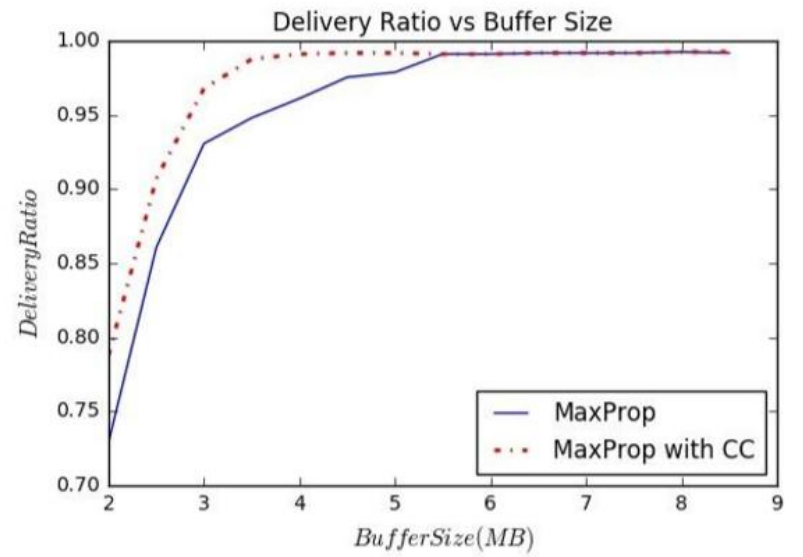

Fig. 4. Delivery ratio Vs varying message Buffer Size (Opportunistic network scenario, band width of $250 \mathrm{Kbps}$, message generation interval of $25-35,126 \mathrm{No}$. of nodes)

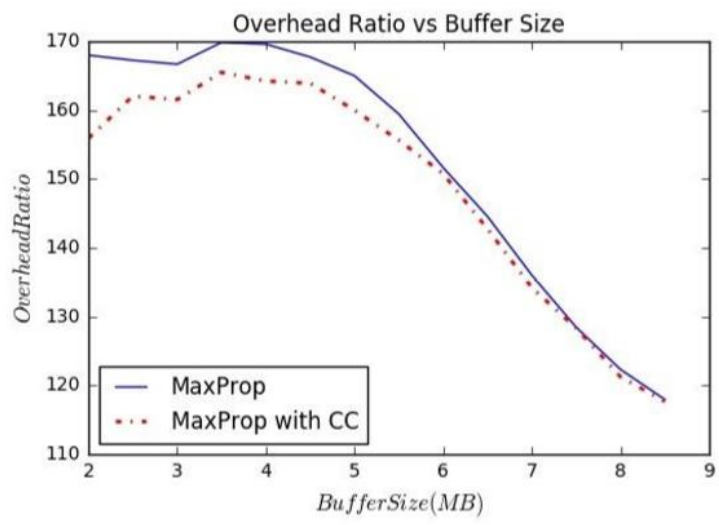

Fig. 5. Overhead ratio Vs varying message Buffer Size (Opportunistic network scenario, bandwidth of $250 \mathrm{Kbps}$, message generation interval of $25-35,126$ No. of nodes)

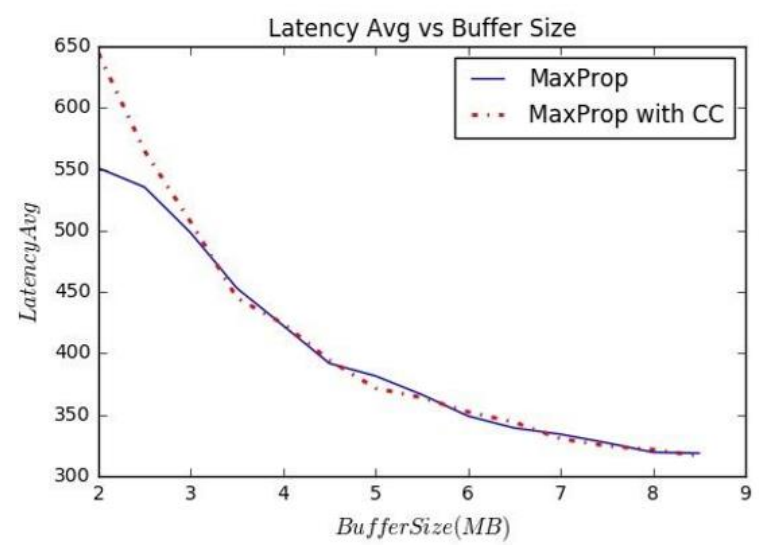

Fig. 6. Average Latency Vs varying message Buffer Size (Opportunistic network scenario bandwidth of $250 \mathrm{Kbps}$, message generation interval of $25-35,126$ No. of nodes)

\section{Conclusion:}

In this work simulations are conducted to evaluate the proposed congestion control methodology and the results are compared with baseline scenario in which no congestion control technique is used. In reality, it is hard to design a protocol which outperforms all the other techniques in the literature for all the parameters. It is practical to compromise one factor in order to attain and improve another parameter. However, the simulation results show that in case of intense traffic, the considerable amount of overhead ratio can be reduced. In general, the average latency is within the tolerable bound while 10 percent increase in delivery probability is observed.

\section{References}

1. Rodrigues, J., Advances in Delay-tolerant Networks (DTNs): Architecture and Enhanced Performance. 2014: Elsevier.

2. Vasilakos, A.V., Y. Zhang, and T. Spyropoulos, Delay tolerant networks: Protocols and applications. 2016: CRC press.

3. Gonçalves Filho, J., et al., A systematic technical survey of DTN and VDTN routing protocols. Computer Standards \& Interfaces, 2016. 48: p. 139-159.

4. Silva, A.P., et al., A survey on congestion control for delay and disruption tolerant networks. Ad Hoc Networks, 2015. 25: p. 480-494.

5. Silva, A.P., et al. Smart Congestion Control for Delay-and Disruption Tolerant Networks. in Sensing, Communication, and Networking (SECON), 2016 13th Annual IEEE International Conference on. 2016. IEEE.

6. Seligman, M., K. Fall, and P. Mundur, Storage routing for DTN congestion control. Wireless communications and mobile computing, 2007. 7(10): p. 1183-1196.

7. Hua, D., et al. A DTN congestion avoidance strategy based on path avoidance. in Future Computer and Communication (ICFCC), 2010 2nd International Conference on. 2010. IEEE.

8. Grundy, A. and M. Radenkovic. Promoting congestion control in opportunistic networks. in 2010 IEEE 6th International Conference on Wireless and Mobile Computing, Networking and Communications. 2010. IEEE.

9. Grundy, A., Congestion control framework for delay-tolerant communications, 2012, University of Nottingham.

10. Yin, L., H.-m. Lu, and J.-m. Gao. An Incentive Congestion Control Strategy for DTNs with Malbehaving Nodes. in Networks Security Wireless Communications and Trusted Computing 
(NSWCTC), 2010 Second International

Conference on. 2010. IEEE.

11. Thompson, N., et al. Retiring Replicants:

Congestion Control for Intermittently-Connected Networks. in INFOCOM. 2010. Citeseer.

12. Radenkovic, M. and A. Grundy. Congestion aware forwarding in delay tolerant and social opportunistic networks. in Wireless On-Demand Network 